\title{
Relationship between thyroid dysfunction and dementia
}

\author{
Ayman M. Elbadawy ${ }^{1}$, Ahmed E. Mansour ${ }^{1 *}$ (D), Ibrahim A. Abdelrassoul ${ }^{2}$ and Rasha O. Abdelmoneim
}

\begin{abstract}
Background: Thyroid hormones are essential for normal development and function of the central nervous system. Thyroid dysfunction is associated with many neuropsychiatric disorders mainly cognitive impairment.

Results: We found a close correlation between thyroid status and cognitive dysfunction. Serum FT3 levels decreased, whereas the serum thyroid-stimulating hormone (TSH) level increased, with the decline in cognitive functions. Furthermore, the TSH level showed a negative correlation with the Mini-Mental State Examination (MMSE) scores. We suggested that thyroid function was associated with cognitive impairments induced by subcortical ischemic vascular dementia (SIVD).

Conclusion: We found that thyroid dysfunction especially subclinical hypothyroidism is associated with cognitive impairment. Dementia increases more with more increase in TSH, and the MMSE score decreases with the increase of age.
\end{abstract}

Keywords: TSH, Dementia, AD, VD, FTD, MMSE

\section{Introduction}

Dementia diminishes the individual's ability to live independently and the quality of life. Dementia, and its most frequent subtype which is Alzheimer's disease, has been associated with thyroid status.

Vascular dementia (VD), also known as vascular cognitive impairment (VCI), results from brain damage due to inadequate blood supply and is the second most common form of dementia only after Alzheimer's disease (AD) [1]. Dementia is defined as a collection of clinical syndromes including impairment of memory, judgment, reasoning, behaviors, and communication abilities and is one of the most disabling conditions affecting the aged population [2]. In the last two decades, thyroid status has emerged as maintenance of normal neural functions. One of the biological mechanisms underlying the relationship between thyroid dysfunction and dementia is suggested to be associated with cardiac vascular disease,

\footnotetext{
* Correspondence: ahmedezzat338@rocketmail.com

'Department of Internal Medicine, Faculty of Medicine, Benha University, Benha, Egypt

Full list of author information is available at the end of the article
}

which can contribute to cognitive impairment in later life [3].

\section{Methods}

This study is a case-control, cross-sectional prospective study that was carried on 40 patients with dementia as well as 10 healthy volunteers as controls. The patients were recruited from the Neurology clinic at Benha University hospitals. All patients were informed about their participation in the study and signed a written consent that was reviewed by the local ethical committee of Benha University.

\section{Inclusion criteria}

Patients aged above 40 with dementia.

\section{Exclusion criteria}

Diagnosis with chronic or degenerative diseases, known thyroid disease, history of brain injury or alcohol abuse, treatment with medication which could influence thyroid or brain function within 4 weeks before the testing, inability to give informed consent.

\section{SpringerOpen}

(c) The Author(s). 2020 Open Access This article is licensed under a Creative Commons Attribution 4.0 International License, which permits use, sharing, adaptation, distribution and reproduction in any medium or format, as long as you give appropriate credit to the original author(s) and the source, provide a link to the Creative Commons licence, and indicate if changes were made. The images or other third party material in this article are included in the article's Creative Commons licence, unless indicated otherwise in a credit line to the material. If material is not included in the article's Creative Commons licence and your intended use is not permitted by statutory regulation or exceeds the permitted use, you will need to obtain permission directly from the copyright holder. To view a copy of this licence, visit http://creativecommons.org/licenses/by/4.0/. 


\section{Study design}

All subjects after giving informed consent were submitted to full medical history with a focus on age, sex, smoking, and body mass index. Sex; the presence of DM, HTN, and IHD; thorough medical examination; and laboratory tests were done as a serum level of TSH, FT3, and FT4 levels.

\section{Statistical analysis}

All collected data were tabulated and analyzed using Statistical Package for Social Science (SPSS) version 16 to obtain:

\section{Descriptive data}

Descriptive statistics were calculated for the data in the form of:

(a) Mean and standard deviation for quantitative data

(b) Frequency and distribution for qualitative data

2. Analytic analysis

(a) Fisher's exact test is used when you have two nominal variables

(b) The Student " $t$ " test compares between 2 means of 2 independent groups; $t$ value is the ratio of the difference between the two means/calculated SD of this difference

(c) Rho $\rightarrow$ Spearman's correlation coefficient: It evaluates the linear association between 2 quantitative variables

(d) The Kruskal-Wallis test (KW test) is used to compare quantitative variables among more than 2 independent groups

\section{Results}

Table 1 shows the demographic characters of the control and cases. Fifty-five percent of the patients were females and $45 \%$ were males in the patient group, while $80 \%$ were females and $20 \%$ were males in the control group. The mean age of patients was $65.9 \pm 13.6$, while in the control group, it is $57.5 \pm 12.6$. There was no significant difference found in the studied groups in age and sex. $P$ is 0.054 and 0.28 in order.

Table 2 shows the comparison of the studied groups as regards the presence of DM. None of the control subjects was diabetic, while $57.5 \%$ of patients were diabetic. There is a statistically significant difference between patients and controls in the presence of DM, and $P$ is 0.001 .

Table 3 shows a comparison between the studied groups as regards HTN. None of the control subjects was hypertensive, while $55.0 \%$ of patients were hypertensive. According to HPT, there was a significant difference between patients and controls, and $P$ is 0.001 statistically significant.

Table 4 shows that serum TSH was significantly high in patients than in the control group. Serum FT3 was significantly low in patients in comparison to the control. There was no statistically significant difference regarding FT4 between patients and the control group. $P$ is $0.03,0.28$, and 0.48 in order.

Table 5 shows a comparison between thyroid dysfunction in the studied groups. $62.5 \%$ of patients had subclinical hypothyroidism, $7.5 \%$ had subclinical hyperthyroid, and $30 \%$ of the patients were euthyroid, while $9 \%$ of the control group were euthyroid and 1\% had subclinical hypothyroidism There was a significant statistical difference in the patients than in the controls, and $P$ is 0.003 (Table 6).

Table 7 compares the degree of dementia according to the history of DM. In patients with MCI, $12.5 \%$ had DM; in patients with mild dementia, $65.2 \%$ had DM; and in patients with moderate dementia, $77.8 \%$ had a history of DM. There was a statistically significant difference between the degree of dementia and DM, when comparing between $\mathrm{MCI}$ and mild dementia, $\mathrm{MCI}$, and moderate dementia. $P$ is 0.015 .

Table 8 compares the degree of dementia according to the history of HTN. In patients with MCI, $0 \%$ had hypertension, while in patients with mild dementia,

Table 1 Demographic characters of the studied sample descriptive data

\begin{tabular}{|c|c|c|c|c|c|c|c|c|c|}
\hline \multirow[t]{2}{*}{ Variable } & & \multicolumn{2}{|c|}{ Patients $(n=40)$} & \multicolumn{2}{|c|}{ Controls $(N=10)$} & \multicolumn{2}{|c|}{ Total $(N=50)$} & \multirow{2}{*}{$\begin{array}{l}\text { Test of } \\
\text { significance }\end{array}$} & \multirow[t]{2}{*}{$P$} \\
\hline & & No. & $\%$ & No. & $\%$ & No. & $\%$ & & \\
\hline \multirow[t]{2}{*}{ Sex } & Male & 18 & 45.0 & 2 & 20.0 & 20 & 40.0 & FET & 0.28 (NS) \\
\hline & Female & 22 & 55.0 & 8 & 80.0 & 30 & 60.0 & & \\
\hline \multirow[t]{3}{*}{ Age (years) } & Mean \pm SD & \multicolumn{2}{|c|}{$65.9 \pm 13.6$} & \multicolumn{2}{|c|}{$57.5 \pm 12.6$} & & & $Z_{\mathrm{MWU}}=1.92$ & 0.054 (NS) \\
\hline & Range & \multicolumn{2}{|c|}{$40-88$} & \multicolumn{2}{|c|}{$40-74$} & & & & \\
\hline & Range & \multicolumn{2}{|c|}{$60-120$} & \multicolumn{2}{|c|}{$70-82$} & & & & \\
\hline
\end{tabular}

FET was used. $P=0.001$ (HS) 
Table 2 Comparison of the studied groups regarding the history of DM

\begin{tabular}{|c|c|c|c|c|c|}
\hline & & & Group & & Total \\
\hline & & & Patients & $\overline{\text { Controls }}$ & \\
\hline$\overline{\mathrm{DM}}$ & No & Count & 17 & 10 & 27 \\
\hline & & $\%$ within group & $42.5 \%$ & $100.0 \%$ & $54.0 \%$ \\
\hline & Yes & Count & 23 & 0 & 23 \\
\hline & & $\%$ within group & $57.5 \%$ & $0.0 \%$ & $46.0 \%$ \\
\hline Total & & Count & 40 & 10 & 50 \\
\hline & & $\%$ within group & $100.0 \%$ & $100.0 \%$ & $100.0 \%$ \\
\hline
\end{tabular}

FET was used. $P=0.001(\mathrm{HS})$

65.2\% had hypertension and in patients with moderate dementia, $77.8 \%$ had a history of HTN. There was a statistically significant difference between HPT and the degree of dementia when comparing between $\mathrm{MCI}$ and mild dementia, MCI, and moderate dementia. $P$ is 0.001 .

Table 9 shows the relation between thyroid dysfunction and degree of dementia. There was a statistically significant difference in thyroid dysfunction with the degree of dementia especially when comparing subclinical hypothyroidism with MCI and mild dementia, MCI, and moderate dementia. $P$ is 0.002 .

Table 10 compares the degree of dementia according to sex. $12.5 \%$ of patients with MCI were males, $43.5 \%$ of patients with mild dementia were males, and $77.8 \%$ of moderate dementia were males, while $87.5 \%$ of patients with MCI were females, $56.5 \%$ of patients with mild dementia were females, and $22.2 \%$ of patients with moderate dementia were females. There was a statistically significant difference when comparing the degree of dementia with sex. $P$ is 0.029 .

Figure 1 compares the MMSE score according to TSH (there was a significant correlation). $P$ is less than 0.001 .

Figure 2 compares the MMSE score according to age (there is a highly significant correlation). $P$ is less than 0.001 .

Table 3 Comparing the studied groups regarding the history of hypertension

\begin{tabular}{|c|c|c|c|c|c|}
\hline & & & \multicolumn{2}{|l|}{ Group } & \multirow[t]{2}{*}{ Total } \\
\hline & & & Patients & Controls & \\
\hline \multirow[t]{4}{*}{$\overline{\text { HTN }}$} & No & Count & 18 & 10 & 28 \\
\hline & & $\%$ within group & $45.0 \%$ & $100.0 \%$ & $56.0 \%$ \\
\hline & Yes & Count & 22 & 0 & 22 \\
\hline & & $\%$ within group & $55.0 \%$ & $0.0 \%$ & $44.0 \%$ \\
\hline \multirow[t]{2}{*}{ Total } & & Count & 40 & 10 & 50 \\
\hline & & $\%$ within group & $100.0 \%$ & $100.0 \%$ & $100.0 \%$ \\
\hline
\end{tabular}

FET was used. $P=0.001(\mathrm{HS})$

\section{Discussion}

In our study, we investigate the relationship between thyroid status, cognitive status, and severity of dementia. Dementia is one of the most disabling conditions affecting the aged population and diminishes the individual's ability to live independently and the quality of life. Besides, it imposes a major burden on the health care system. Therefore, it would be of great advantage if modifiable risk factors for dementia could be identified [2].

Thyroid hormones have been demonstrated to play central roles in the development of the central neural system. The relation between thyroid functional state and the risk of AD and VD has been widely investigated, by assessing the serum levels of thyroid hormone including FT3, thyroxin (FT4), and TSH. Both subclinical hyper- and hypothyroidism have been established as risk factors for cognitive impairment [2]. The American Association of Clinical Endocrinologists (AACE) has proposed modifying target $\mathrm{TSH}$ levels from the widely accepted 0.5 to $5.0 \mathrm{mU} / \mathrm{L}$ to the narrower range 0.3 to $3.04 \mathrm{mU} / \mathrm{L}$.

The National Association of Clinical Biochemistry argues that the upper limit of serum TSH euthyroid range should be reduced to $2.5 \mathrm{mU} / \mathrm{L}$, citing data that over $95 \%$ of rigorously screened normal. Both clinical and subclinical hypothyroidism have been shown by several although not all studies to affect cardiovascular risk.

Hyperthyroidism is associated with an increase in vascular basement membrane thickness and capillary destruction. In parallel, vascular risk factors have been correlated with an increase in the risk for AD. Thus, through an increase in vascular risk factors, thyroid function may indirectly affect AD risk (Tan et al.,2006).

In our study, we found that there is a strong link between high thyroid dysfunction and risk (Tables 5 and 6) and the degree of dementia (Table 9). One of the biological mechanisms underlying the relationship between thyroid dysfunction and dementia is suggested to be associated with cardiac vascular disease, which can contribute to cognitive impairment in later life. Our results were in agreement with Davis et al. who proposed thyroid hormones as risk predictors of dementia. Subclinical hypothyroidism with T4 and elevated TSH has been identified as a common predisposing factor of depression, cognitive impairment, and dementia [4].

Also, this was concordant with Carole Rieben et al. who found that the risk of dementia increases with more increase in TSH level. Among older adults, subclinical hyperthyroidism with a TSH $<0.10 \mathrm{mIU} / \mathrm{L}$ was associated with a higher risk of dementia and a larger cognitive decline, while subclinical hyperthyroidism with mildly decreased TSH or subclinical hypothyroidism were not [5]. 
Table 4 Comparing the studied groups regarding thyroid function tests

\begin{tabular}{|c|c|c|c|c|c|c|c|c|}
\hline \multirow[t]{2}{*}{ Variable } & \multicolumn{3}{|c|}{ Patients $(n=40)$} & \multicolumn{3}{|c|}{ Controls $(N=10)$} & \multirow{2}{*}{$\begin{array}{l}Z_{\text {MWU }} \\
\text { test }\end{array}$} & \multirow[t]{2}{*}{ P } \\
\hline & Mean & $\pm \mathrm{SD}$ & Range & Mean & $\pm \mathrm{SD}$ & Range & & \\
\hline TSH & 3.99 & 2.28 & $0.81-8.32$ & 2.31 & 0.99 & $1.04-4.31$ & 2.16 & $0.03(\mathrm{~S})$ \\
\hline FT3 & 2.14 & 1.65 & $0.25-7.92$ & 3.02 & 0.49 & $2.32-3.76$ & 2.19 & $0.028(S)$ \\
\hline FT4 & 1.52 & 0.91 & $0.01-3.77$ & 1.47 & 0.36 & $1.1,2.3$ & 0.70 & 0.48 (NS) \\
\hline
\end{tabular}

Also, this was concordant with Scherr et al. who found that cognitive function was closely related with serum $\mathrm{T} 3$, which has been widely characterized to be a notable preventive and therapeutic target in thyroid disorders, and even in neuropsychological diseases [6,7].

Also, this was in agreement with Shindo et al. who attributed the relation of dementia and FT3 to the critical roles of $\mathrm{T} 3$ in the maintenance of inner mitochondrial membrane fluidity and permeability through regulating the fatty acid and phospholipid composition of the membrane. It is likely that T3 deficiency may lead to the onset of mitochondrial dysfunctions, thus affecting brain metabolic activity and intracellular signal transduction and contributing to the cerebral ischemia [8].

Also, this was concordant with Chen et al. who found higher serum TSH and lower T3 levels may be associated with cognitive impairment induced by SIVD and recognized the neuropsychological features of VD stages [9].

Also, this was concordant with Annerbo and Lökk who found the association between TSH and cognitive impairment in community-dwelling and hospitalized elderly [10].

This was in agreement with Hogervorst et al. who reported that cognition was investigated at baseline and after a 2-year follow-up in 1047 participants over 64 years of age, without physical frailty or severe cognitive impairment at baseline, and found an association between high FT4 levels and an accelerated cognitive decline as well as dementia progression [11].

Also, this was not concordant with Hofman and his colleagues who, in the Rotterdam Study, after adjustment for variables including age, sex, and cardiovascular disease risk factors, showed that those with higher thyroid-stimulating hormone (TSH) levels-typically a sign of an underactive thyroid-had a lower risk of dementia [12].

This was not concordant with Jorde et al. who found lack of association between subclinical hypothyroidism and cognitive impairment is also in line with the results of other placebo-controlled randomized clinical trials $[13,14]$.

This was not concordant with Roberts et al. who showed a lack of association between subclinical hypothyroidism and cognitive impairment that largely drew upon the results from large population-based studies [15].

In our study, we found that the increase in TSH level is associated with more decrease in MMSES and AD and VD patients with the worse cognitive performance presented distinctly lower MMSE scores than the healthy control, and there was a significant link between TSH concentrations and patients converting from mild

Table 5 Comparison of the studied groups regarding thyroid dysfunction

\begin{tabular}{|c|c|c|c|c|}
\hline & & \multicolumn{2}{|l|}{ Group } & \multirow[t]{2}{*}{ Total } \\
\hline & & Patients & Controls & \\
\hline \multirow[t]{2}{*}{ Euthyroid } & Count & 12 & 9 & 21 \\
\hline & $\%$ within group & $30.0 \%$ & $90.0 \%$ & $42.0 \%$ \\
\hline \multirow[t]{2}{*}{ Overt hypothyroidism } & Count & 0 & 0 & 0 \\
\hline & $\%$ within group & 0 & $0 \%$ & $0 \%$ \\
\hline \multirow[t]{2}{*}{ Subclinical hypothyroidism } & Count & 25 & 1 & 26 \\
\hline & $\%$ within group & $62.5 \%$ & $10.0 \%$ & $52.0 \%$ \\
\hline \multirow[t]{2}{*}{ Overt hyperthyroidism } & Count & 0 & 0 & 0 \\
\hline & $\%$ within group & 0 & $0 \%$ & $0 \%$ \\
\hline \multirow[t]{2}{*}{ Subclinical hyperthyroidism } & Count & 3 & 0 & 3 \\
\hline & $\%$ within group & $7.5 \%$ & $0 \%$ & $6.0 \%$ \\
\hline \multirow[t]{2}{*}{ Total } & Count & 40 & 10 & 50 \\
\hline & $\%$ within group & $100.0 \%$ & $100.0 \%$ & $100.0 \%$ \\
\hline
\end{tabular}

$\mathrm{FET}=10.9 . P=0.003(\mathrm{~S})$ 
Table 6 Distribution of the degree of dementia according to age

\begin{tabular}{|c|c|c|c|c|c|c|c|c|c|}
\hline \multirow[t]{2}{*}{ Variable } & \multicolumn{2}{|c|}{ Mild cog impairment $(N=8)$} & \multicolumn{2}{|c|}{ Mild dementia $(N=23)$} & \multicolumn{2}{|c|}{ Moderate dementia $(N=9)$} & \multirow[t]{2}{*}{ KWT } & \multirow[t]{2}{*}{$P$} & \multirow[t]{2}{*}{ Sig pairs } \\
\hline & $\overline{M e a n}$ & $\pm S D$ & $\overline{M e a n}$ & $\pm S D$ & $\overline{M e a n}$ & $\pm S D$ & & & \\
\hline Age (years) & 45.7 & 6.84 & 71.9 & 10.01 & 72.7 & 5.86 & 17.4 & $<0.001(\mathrm{HS})$ & $\begin{array}{l}\text { Mild cog } \neq \text { mild dementia } \\
\text { Mild cog } \neq \text { mod dementia }\end{array}$ \\
\hline
\end{tabular}

cognitive impairment to Alzheimer's disease. This was concordant with Zongsheng Chen who found that a close correlation between thyroid status and cognitive dysfunction in SIVD was observed. Serum TT3 and FT3 levels decreased, whereas serum TSH level increased, with the decline in cognitive functions. Furthermore, TT3 levels showed a positive correlation, whereas TSH level showed a negative correlation, with the MiniMental State Examination (MMSE) scores, suggesting that thyroid function was associated with cognitive impairments induced by SIVD. Also, thyroid function and thyroid hormone level could be a risk factor in the development of SIVD. Serum TT3 and TSH levels might also be used as biomarkers for cognitive dysfunction [9].

Also, this was concordant with Johe who found a linear relationship between thyroid hormone and MMSE scores was conducted. Higher TSH and lower T3 significantly lowered the MMSE scores, which indicated worse cognitive performance. A central role of T3 in neuronal differentiation has been uncovered, which directed stem cells to generate clones of neuro-oligodendrocytes from the central nervous system [16].

Also, this was concordant with [17]. who found that VD patients with worse cognitive performance presented distinctly lower MMSE scores than the healthy control. The cognitive performance of VD patients was significantly declined, as indicated by the significantly altered scores of several neuropsychological tests, for example MMSE as measurements of global cognitive function.

Also, this was in agreement with Roman et al. who indicated a consistent positive correlation between TSH levels and cognitive decline in VD. However, most of the associations found in subclinical hypothyroidism concerned participants in particular with a TSH level of 5 $\mathrm{mIU} / \mathrm{L}$ or above [18].
But this was not concordant with Jorde et al. who found that there was a lack of association between subclinical hypothyroidism, high TSH, and cognitive impairment and MMSE which was also concordant with the results of two placebo-controlled randomized clinical trials which stated the same results [13].

In our study, we found that dementia increases in the presence of DM (Table 2). There was a relationship between impaired glucose tolerance and stroke-related dementia as DM is one of many other risk factors of vascular disease.

This was in agreement with the Rotterdam study which included 9446 participants with a mean age of 65 years. During follow-up (mean 8.0 years), 601 participants had developed dementia and it was found that diabetes is an attributable risk for dementia of which $8.8 \%$ suggests that diabetes may have contributed to the clinical syndrome in a substantial proportion of all dementia patients [19].

This was not concordant with J.D. Curb et al. who found that there is no association between $\mathrm{AD}$ and diabetes, present either 25 or 15 years previously; it was found after adjustment for age and education in a multiple regression model [20].

In our study, we found that dementia increases in the presence of hypertension which is one of the many risk factors of vascular disease.

This was in agreement with Nelson et al. who found that previously increased blood pressure may increase the risk for dementia by inducing small-vessel disease and white-matter lesions. To what extent the decline in blood pressure before dementia onset is a consequence or a cause of the brain disease remains to be elucidated [21].

This was not concordant with Luchsinger et al. who found that hypertension after age 65 years is not

Table 7 Distribution of the degree of dementia according to the history of DM

\begin{tabular}{|c|c|c|c|c|c|c|}
\hline & & & \multicolumn{3}{|l|}{ Dementia degree } & \multirow[t]{2}{*}{ Total } \\
\hline & & & Mild cog impairment & Mild dementia & Moderate dementia & \\
\hline \multirow[t]{4}{*}{$\overline{D M}$} & No & Count & 7 & 8 & 2 & 17 \\
\hline & & $\%$ & $87.5 \%$ & $34.8 \%$ & $22.2 \%$ & $42.5 \%$ \\
\hline & Yes & Count & 1 & 15 & 7 & 23 \\
\hline & & $\%$ & $12.5 \%$ & $65.2 \%$ & $77.8 \%$ & $57.5 \%$ \\
\hline \multirow[t]{2}{*}{ Total } & & Count & 8 & 23 & 9 & 40 \\
\hline & & $\%$ & $100.0 \%$ & $100.0 \%$ & $100.0 \%$ & $100.0 \%$ \\
\hline
\end{tabular}

$\mathrm{FET}=$ 8.3. $P=0.015(\mathrm{~S})$ 
Table 8 Distribution of the degree of dementia according to the history of hypertension

\begin{tabular}{|c|c|c|c|c|c|c|}
\hline & & & Dementia degree & & & Total \\
\hline & & & Mild cog impairment & Mild dementia & Moderate dementia & \\
\hline HTN & No & Count & 8 & 8 & 2 & 18 \\
\hline & & $\%$ & $100.0 \%$ & $34.8 \%$ & $22.2 \%$ & $45.0 \%$ \\
\hline & Yes & Count & 0 & 15 & 7 & 22 \\
\hline & & $\%$ & $0.0 \%$ & $65.2 \%$ & $77.8 \%$ & $55.0 \%$ \\
\hline Total & & Count & 8 & 23 & 9 & 40 \\
\hline & & $\%$ & $100.0 \%$ & $100.0 \%$ & $100.0 \%$ & $100.0 \%$ \\
\hline
\end{tabular}

$\mathrm{FET}=$ 12.9. $P=0.001(\mathrm{HS})$

associated with $\mathrm{AD}$ and does not adversely affect memory, language, or general cognitive function. A history of hypertension may be an antecedent to $\mathrm{VD}$, particularly in the presence of heart disease or diabetes [22].

In our study, we found that the degree of dementia increases with FT3 decrease and TSH increase (hypothyroidism) but with no relation with the FT4 level.

This was concordant with Francesco et al. who found that lower TSH levels were found to be predictive factors of AD progression in subjects with mild cognitive impairment [23].

But this was not in agreement with Hogervorst et al. who reported that cognition was investigated at baseline and after a 2-year follow-up in 1047 participants over 64 years of age, without physical frailty or severe cognitive impairment at baseline, and found an association between high FT4 levels and an accelerated cognitive decline as well as dementia progression. It is unclear why high normal FT4 levels were independently associated with accelerated cognitive decline in those without overt thyroid disease [11].
In our study, we found an increase severity of dementia with age. Patients with mild dementia and those with moderate dementia are older than those with MCI. People are living longer, and dementia is becoming more common in the population as a whole.

This was in agreement with Constantine et al. who found that the severity of dementia increases with age (American Journal of Psychiatry as the mean of age was 74 and severity increased with age) [24].

Also, this was in agreement with [25] who found the same results.

This was not in agreement with Holland et al. who found that dementia and $\mathrm{AD}$ severity decrease with age as they found that the phenotypic expression of $\mathrm{AD}$ is relatively mild in individuals older than approximately 85 years, and this may affect the ability to distinguish $\mathrm{AD}$ from normal aging in the very old ([26],).

In our study, we found that the dementia degree increases more in females. The relationship between sex and AD has been inconsistent across studies although in many studies women are reported to have higher rates

Table 9 Relation between the degree of dementia and thyroid dysfunction

\begin{tabular}{|c|c|c|c|c|c|}
\hline & & \multicolumn{3}{|l|}{ Dementia degree } & \multirow[t]{2}{*}{ Total } \\
\hline & & Mild cog impairment & Mild dementia & Moderate dementia & \\
\hline \multirow[t]{2}{*}{ Euthyroid } & Count & 4 & 5 & 3 & 12 \\
\hline & $\%$ & $50.0 \%$ & $21.7 \%$ & $33.3 \%$ & $30.0 \%$ \\
\hline \multirow[t]{2}{*}{ Overt hypothyroidism } & Count & 0 & 0 & 0 & 0 \\
\hline & $\%$ & $0 \%$ & $0 \%$ & $0 \%$ & $0 \%$ \\
\hline \multirow[t]{2}{*}{ Subclinical hypothyroidism } & Count & 1 & 18 & 6 & 25 \\
\hline & $\%$ & $12.5 \%$ & $78.3 \%$ & $66.7 \%$ & $62.5 \%$ \\
\hline \multirow[t]{2}{*}{ Overt hyperthyroidism } & Count & 0 & 0 & 0 & 0 \\
\hline & $\%$ & $0 \%$ & $0 \%$ & $0 \%$ & $0 \%$ \\
\hline \multirow[t]{2}{*}{ Subclinical hyperthyroidism } & Count & 3 & 0 & 0 & 3 \\
\hline & $\%$ & $37.5 \%$ & $0.0 \%$ & $0.0 \%$ & $7.5 \%$ \\
\hline \multirow[t]{2}{*}{ Total } & Count & 8 & 23 & 9 & 40 \\
\hline & $\%$ & $100.0 \%$ & $100.0 \%$ & $100.0 \%$ & $100.0 \%$ \\
\hline
\end{tabular}

$\mathrm{FET}=13.8 . P=0.002(\mathrm{~S})$ 
Table 10 Distribution of the degree of dementia according to sex

\begin{tabular}{|c|c|c|c|c|c|c|}
\hline & & & \multicolumn{3}{|l|}{ Dementia degree } & \multirow[t]{2}{*}{ Total } \\
\hline & & & Mild cog impairment & Mild dementia & Moderate dementia & \\
\hline \multirow[t]{4}{*}{ Sex } & Male & Count & 1 & 10 & 7 & 18 \\
\hline & & $\%$ & $12.5 \%$ & $43.5 \%$ & $77.8 \%$ & $45.0 \%$ \\
\hline & Female & Count & 7 & 13 & 2 & 22 \\
\hline & & $\%$ & $87.5 \%$ & $56.5 \%$ & $22.2 \%$ & $55.0 \%$ \\
\hline \multirow[t]{2}{*}{ Total } & & Count & 8 & 23 & 9 & 40 \\
\hline & & $\%$ & $100.0 \%$ & $100.0 \%$ & $100.0 \%$ & $100.0 \%$ \\
\hline
\end{tabular}

$\mathrm{FET}=7.07 . P=0.029(\mathrm{~S})$

of $\mathrm{AD}$ than men even after adjusting for differential survival. Significant differences between sex usually occur.

This was concordant with Pike et al. who found that an association between sex and $\mathrm{AD}$ assumes a greater significance as there is increasing evidence that estrogen replacement therapy in postmenopausal women improves cognitive function and reduces the risk for both cognitive impairment and $\mathrm{AD}$ [27].

This was concordant with Hotze Health who worked on around 2000 patients who were evaluated for dementia over the course of 13 years. In that time, 209 patients developed Alzheimer's. The study concluded that women with the lowest serum concentrations of TSH and those with the highest concentrations were more than twice as likely to develop Alzheimer's disease than the women with normal/mid-range levels. The study was unable to determine the same sort of link among men [28].

In Framingham study, participants were followed up for a period of 12.7 years, close to 2000 participants who were tested periodically for thyroid function using thyroid-stimulating hormone (TSH) levels and tested for dementia using the Mini-Mental Status Examination (MMSE). A relationship one way or the other was thought to maybe be found, but it was interesting to find that both low and high levels of TSH were associated with Alzheimer's disease. It is also unclear why thyroid hormone levels affect Alzheimer's disease risk in women but not in men. It may be that the brain of women or the hormonal milieu of women makes them more prone to this effect [29].

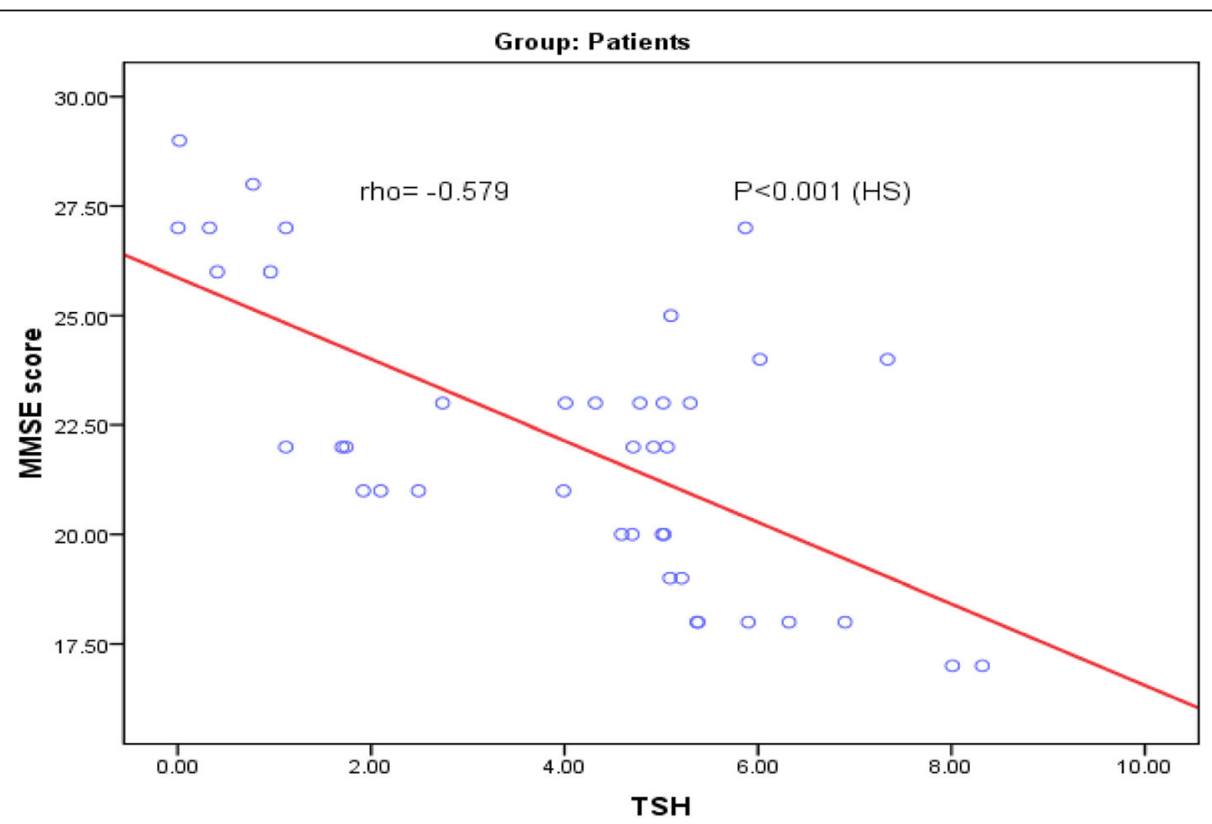

Fig. 1 Scatter graph showing a highly significant negative correlation between TSH and MMSE score 


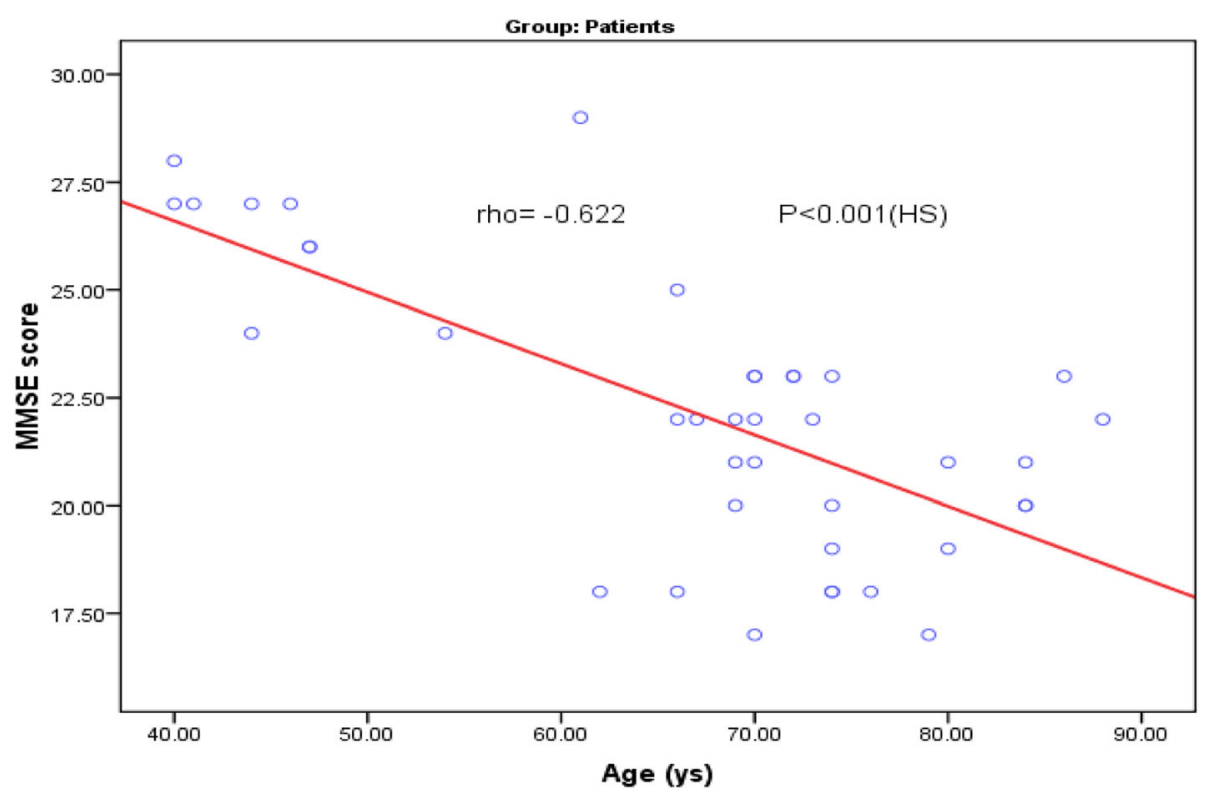

Fig. 2 Scatter graph showing a highly significant negative correlation between age and MMSE score

\section{Conclusion}

We found that thyroid dysfunction especially subclinical hypothyroidism is associated with cognitive impairment. Dementia increases more with more the increase in TSH, and the MMSE score decreases with the increase of age. So we suggest screening for subclinical hypothyroidism in all patients with cognitive dysfunction.

\section{Abbreviations}

TSH: Thyroid-stimulating hormone; FT3: Tri-iodothyronine; FT4: Thyroxin; DM: Diabetes mellitus; HTN: Hypertension; VD: Vascular dementia;

AD: Alzheimer disease; MCI: Mild cognitive impairment; MMSES: Mini-Mental Status Examination Score: SIVD: Subcortical ischemic vascular dementia; FTD: Frontotemporal dementia

\section{Acknowledgements}

Not applicable

\section{Authors' contributions}

A.E contributed to the data collection, design of the study, and writing of the discussion. E.A. contributed to the study design, interpretation of data, writing of the discussion, and results; drafted the work and revised it; and created the new software used in the work. I.A contributed to the data collection and writing of the discussion and revised the data. R.O contributed to the data collection and interpretation, the creation of new software used in the work, and the writing of the discussion and results. The authors read and approved the final manuscript.

\section{Funding}

No funding was received.

\section{Availability of data and materials}

The datasets used and/or analyzed during the current study are available from the corresponding author on reasonable request.

\section{Ethics approval and consent to participate}

This study was approved by the ethics committee of Benha Faculty of Medicine, Benha University with approval number 2017- 163.

A written consent was obtained from all participants in the study.

\section{Consent for publication}

Not applicable

\section{Competing interests}

No financial and non-financial competing interests

\section{Author details}

'Department of Internal Medicine, Faculty of Medicine, Benha University, Benha, Egypt. ${ }^{2}$ Department of Neuropsychiatry, Faculty of Medicine, Benha University, Benha, Egypt.

Received: 14 May 2020 Accepted: 18 June 2020

Published online: 06 October 2020

\section{References}

1. Moretti RP, Torre RM, Antonello T, Cattaruzza G, Bava CA (2005) Vascular cognitive impairment: current concepts and clinical developments. Lancet Neurol 7:246-255

2. Kawas $\mathrm{CH}$, Corrada MM (2006) Subclinical hyperthyroidism and risk of dementia. Clin Endocrinol 53:733-737

3. Wijman, L.W, Aj, DE, Crean, S., Trompet, J, Gussekloo, D. J and N. Ronaldo, (2013): Thyroid function and risk of Alzheimer, Arch.inter.med. Int. J. Alzheimer's Dis, 303-308

4. Davis JD, Stern RA, Flashman LA (2003) Cognitive and neuropsychiatric aspects of subclinical hypothyroidism: significance in the elderly. Current Psychiatry Reports 5(5):384-390

5. Carole Rieben, Daniel Segna, Bruno R. da Costa, Tinh-Hai, Collet Layal and Chaker (2016): Risk of cognitive decline: a meta-analysis of prospective cohort studies. The Journal of Clinical Endocrinology \& Metabolism, Volume 101, Issue 12, 1 Pages 4945-4954

6. Scherr, MY., Krenn, C., Sorg, A., Manoliu, E., Trenkaand H. Forsstle (2014): Subcortical ischaemic vascular dementia. Lancet Neurol. 1:426-436

7. Lin L, Xue Y, Duan Q, Sun B, Chen X (2015) Alzheimer's and dementia in the oldest-old: a century of challenges. Curr Alzheimer Res 3:411-419

8. Shindo AA, Liang C, Maki T, Miyamoto N, Tomimoto N (2016) Cortical thinning in vascular mild cognitive impairment and vascular dementia of subcortical type. J Neuroimaging 20:37-45

9. Zongheng Chen,(2016): Thyroid status and cognitive impairment in SIVD; 481-491

10. Annerbo S and Lökk J (2013): A clinical review of the association of thyroid stimulating hormone and cognitive impairment. ISRN Endocrinol. 2013; 2013: 856017 
11. Hogervorst EF, Huppert F, Matthews E, Brayne C (2008) Association between dementia and elevated TSH: a community-based study. Biol Psychiatry 40: 714-725

12. Hofman A, Breteler MMB, van Duijn CM, Janssen HLA, Krestin GP, Kuipers EJ (2010) The Rotterdam study: 2010 objectives and design update. European Journal of Epidemiology volume 24:553-572

13. Johan J, Knut SJ (2006) Neuropsychological function and symptoms in patients with subclinical hypothyroidism. Jof clinical endocrinology 91:145-153

14. J Parle, L Roberts, S Wilson, H Pattison, A Roalfe, M S Haque, C Heath, M Sheppard, J Franklyn, F D R Hobbs (2010): A randomized controlled trial of the effect of thyroxine replacement on cognitive function in communityliving elderly subjects with subclinical hypothyroidism: the Birmingham elderly thyroid study. J Clin Endocrinol Metab 2010 Aug;95(8):3623-3632

15. Roberts, L. M., H. Pattison, A. Roalfe, J. Franklyn, S. Wilson, F. D. Hobbs, et al. (2006): Is subclinical thyroid dysfunction in the elderly associated with depression?

16. Johe KK, Hazel TG, Muller T, Dugich-Djordjevic MM, McKay RD (1996) Single factors direct the differentiation of stem cells from the fetal and adult central nervous system. Genes Dev 10:3129-3140

17. Frisoni GB, Galluzzi S, Bresciani L, Zanetti O, Geroldi C (2002) Serum thyroidstimulating hormone as a predictor of cognitive impairment in an elderly cohort. Gerontology 58:41-49

18. Roman GC, Erkinjuntti T, Wallin A, Pantoni L, Chui HC (2002) Subcortical ischaemic vascular dementia. Lancet Neurol 1:426-436

19. Hofman A, Guy G. O. Brusselle, Sarwa Darwish Murad, Cornelia M. van Duijn, Oscar H. Franco, et al (2016): The Rotterdam study: 2016 objectives and design update Eur J Epidemiol. 2015; 30: 661-708.Published online 2015 Sep 19. doi: https://doi.org/10.1007/s10654-015-0082-3

20. JD Curb, (1999): Association of vascular dementia and diabetes, neurology.52

21. Nelson L, Tabet N Slowing the progression of Alzheimer's disease; what works? (2015) Ageing Research Reviews Volume 23, Part B, September 2015, Pages 193-209

22. Luchsinger (2001): HPT, DM and risk of Alzheimer disease. vol,154,635-641

23. Francesco, Antonio, Marzia, Grigolito and Domenico. (2017). Pathophysiology of vascular dementia .the American Geriatric Society, 2000. vol.48:775-782

24. Constantine G. Lyketsos, M.D., M.H.S., Jeannie-Marie E. Sheppard, B.A., and Peter V. Rabins, M.D., M.P.H.(2000): Dementia in elderly persons in a general hospital. Am J Psychiatr Volume 157 Issue 5 May 2000 Pages 704-707

25. María M. Corrada, Ron Brookmeyer, Annlia Paganini-Hill, Daniel Berlau, and Claudia H. Kawas (2010): Dementia incidence continues to increase with age in the oldest old: the 90+ study s:Ann Neurol. 2010 Jan; 67(1): 114-121. doi: https://doi.org/10.1002/ana.21915

26. Holland D, Rahul S. Desikan, Anders M. Dale, Linda K. McEvoy, and for the Alzheimer's Disease Neuroimaging Initiative(2012): Rates of decline in Alzheimer disease decrease with age. Published online 2012 Aug 2. doi: 10. 1371/journal.pone.0042325

27. Christian J Pike, Jenna C Carroll, Emily R Rosario, Anna M Barron(2009): Protective actions of sex steroid hormones in Alzheimer's disease. Front Neuroendocrinol 30(2):239-258 · June 2009 with 213 Reads DOl: https:// doi.org/10.1016/j.yfrne.2009.04.015

28. hotze health 2017

29. Tan ZS, Beiser A, Vasan RS, Au R, Auerbach S, Kiel DP et al (2008) Thyroid function and the risk of Alzheimer disease: the Framingham study. Arch Intern Med 168:1514-1520

\section{Publisher's Note}

Springer Nature remains neutral with regard to jurisdictional claims in published maps and institutional affiliations.

\section{Submit your manuscript to a SpringerOpen ${ }^{\circ}$ journal and benefit from:}

- Convenient online submission

- Rigorous peer review

- Open access: articles freely available online

High visibility within the field

- Retaining the copyright to your article

Submit your next manuscript at $\boldsymbol{\nabla}$ springeropen.com 